\section{Effect of Oyster Shell Supplementation to the Culture Medium on Anthocyanin Content in the Spathe of Anthurium andraeanum Lind.}

\author{
Xia Chun-hua \\ Department of Landscape Architecture, Guangdong Ocean University, \\ Zhanjiang, Guangdong, 524088 China; and College of Forestry, Central \\ South University of Forestry and Technology, Changsha, Hunan, 410004 China \\ Chen Jian-hua \\ College of Forestry, Central South University of Forestry and Technology, \\ Changsha, Hunan 410004 China
}

Additional index words. anthocyanin, Anthurium andraeanum Lind., nitrogen, oyster shell, phosphorous

\begin{abstract}
Anthurium andraeanum Lind. is an economically important potted and freshcut flower species. However, reduced anthocyanin content under shaded cultivation impacts the color of the spathe, which has negative implications for the marketability of $A$. andraeanum. Thus, the present study evaluates the use of oyster shell supplementation to the cultivation medium for improving anthocyanin content. Appropriate calcium (Ca) can improve the activity of phenylalanine ammonia lyase (PAL), and PAL activity is positively correlated with anthocyanin content; nitrogen $(N)$ and phosphorus (P) nutrients are closely related to anthocyanin synthesis. $N$ and $P$ nutrients and $C a$ can alleviate the color symptoms of $A$. andraeanum when anthocyanin content decreases under weak light (under $220 \mu \mathrm{mol} \cdot \mathrm{m}^{-2} \cdot \mathrm{s}^{-1}$ ). Microdissolution of calcium carbonate, the main component of oyster shell, can provide better exogenous Ca and adsorb slowrelease $N$ and $P$. Selecting appropriate oyster shell fragments will be the key to $A$. andraeanum experimental cultivation under low light conditions. Using regression models and response surface methodology (RSM), the relationships between oyster shell fragments and anthocyanin content are promulgated. The main findings indicated that the Ca released from 286-mg oyster shell fragments at $\mathrm{pH} 5.5$ significantly increased the activity of PAL in the pedicel under weak light within 8 hours. At pH 5.9, 375-mg oyster shell fragments could significantly adsorb $N$ and $P$ nutrients within 4 to 14 hours. In conclusion, 286 to $375 \mathrm{mg}$ oyster shell fragments at pH 5.5 to 5.9 could stabilize slowrelease fertilizer source and significantly increase anthocyanin content in $A$. andraeanum spathe.
\end{abstract}

Anthurium andraeanum Lind. (Araceae) is an economically important tropical potted and fresh-cut ornamental flower species (Dufour and Guerin, 2003). Studies have shown that reduced light intensity under conditions of excessive shading or prolonged low temperature and rainfall in cultivation facilities leads to the fading of the spathe ( $\mathrm{Li}$ et al., 2015; Wang et al., 2012), which seriously impacts the quality and marketability of $A$. andraeanum flowers (Chang et al., 2012).

Received for publication 10 June 2019. Accepted for publication 8 July 2019 .

This research was funded by the Guangdong Science and Technology Project, "Inhibitory Effect of Soilless Culture Medium on Greenback in the Spathe of Anthurium andraeanum" (2013B020302007).

C.J. is the corresponding author. E-mail: 10542022@ qq.com.

This is an open access article distributed under the CC BY-NC-ND license (http://creativecommons.org/ licenses/by-nc-nd/4.0/).
2019). Calcium carbonate can provide a good source of exogenous $\mathrm{Ca}$ in the soilless cultivation of $A$. andraeanum and can be used in the cultivation matrix. Oyster shells have a naturally porous surface and good solubility, adsorption, and chemical activity (Liu, 2004)' and can adsorb ammonium nitrogen $\left(\mathrm{NH}_{4}{ }^{+}-\mathrm{N}\right)$. The use of oyster shell in the preparation of slow-release nitrogen fertilizer (Miao et al., 2007) can also alleviate the loss of $\mathrm{N}$. The soilless cultivation of $A$. andraeanum using oyster shells depends on the size of the oyster shell fragments and the $\mathrm{pH}$ value of the solution. These two factors are closely associated with the dissolution of calcium carbonate and the absorption of $\mathrm{N}$ and $\mathrm{P}$, and the factors may affect the quality of $A$. andraeanum.

The use of oyster shells for the supplementation of $\mathrm{Ca}$ in the cultivation medium of $A$. andraeanum has not been previously investigated. The present study thus aimed to test the use of soilless cultivation using oyster shell for increasing anthocyanin content in $A$. andraeanum by 1 ) determining the $\mathrm{N}$ and $\mathrm{P}$ absorption of differently sized oyster shell fragments, 2) evaluating the effect of different $\mathrm{pH}$ values on the release of $\mathrm{Ca}$ from the shells, 3 ) assessing the impact of temperature and light intensity on PAL activity and anthocyanin content, 4) evaluating the effects of oyster shell fragment mass and cultivation time on PAL activity in the pedicles, and 5) determining the changes in $\mathrm{Ca}^{2+}$ in the pedicles and anthocyanin content in the spathe under cultivation with oyster shells.

\section{Materials and Methods}

\section{Materials}

A 3-year-old red variety of $A$. andraeanum called 'Tropical' was grown in the Landscape Practice Teaching Base of Guangdong Ocean University (Zhanjiang, China). It was cultivated in a 5-L flow aquarium using a general nutrient solution for $A$. andraeanum supplemented with oyster shell fragments (one plant per box). Its new leaf sheath had been exposed for one week and was bronze in color. Fivecentimeter-long flower branches were obtained, from which the pedicels were used for the determination of Ca and PAL, while the spathe was used for anthocyanin content determination. The oyster shells (collected from Zhanjiang market waste) were immersed in a $0.1 \%$ hydrochloric acid solution for $10 \mathrm{~h}$. The surface sediment was cleaned using a wire brush, then the shells were dried naturally in a ventilated area. The oyster shells were crushed using a grinder and then screened.

\section{Methods}

Adsorption of the oyster shell fragments. The adsorption of total nitrogen (TN), ammonia nitrogen $\left(\mathrm{NH}_{4}{ }^{+}-\mathrm{N}\right)$, and total phosphorus (TP) by the differently sized oyster shell fragments in the general nutrient solution (Wang, 1997) was determined at different time periods. The optimum cultivation $\mathrm{pH}$ value for $A$. andraeanum was previously determined to be 5.5 to 6.5. Oyster shell fragments with masses of 
$\mathrm{T}(\mathrm{h})$

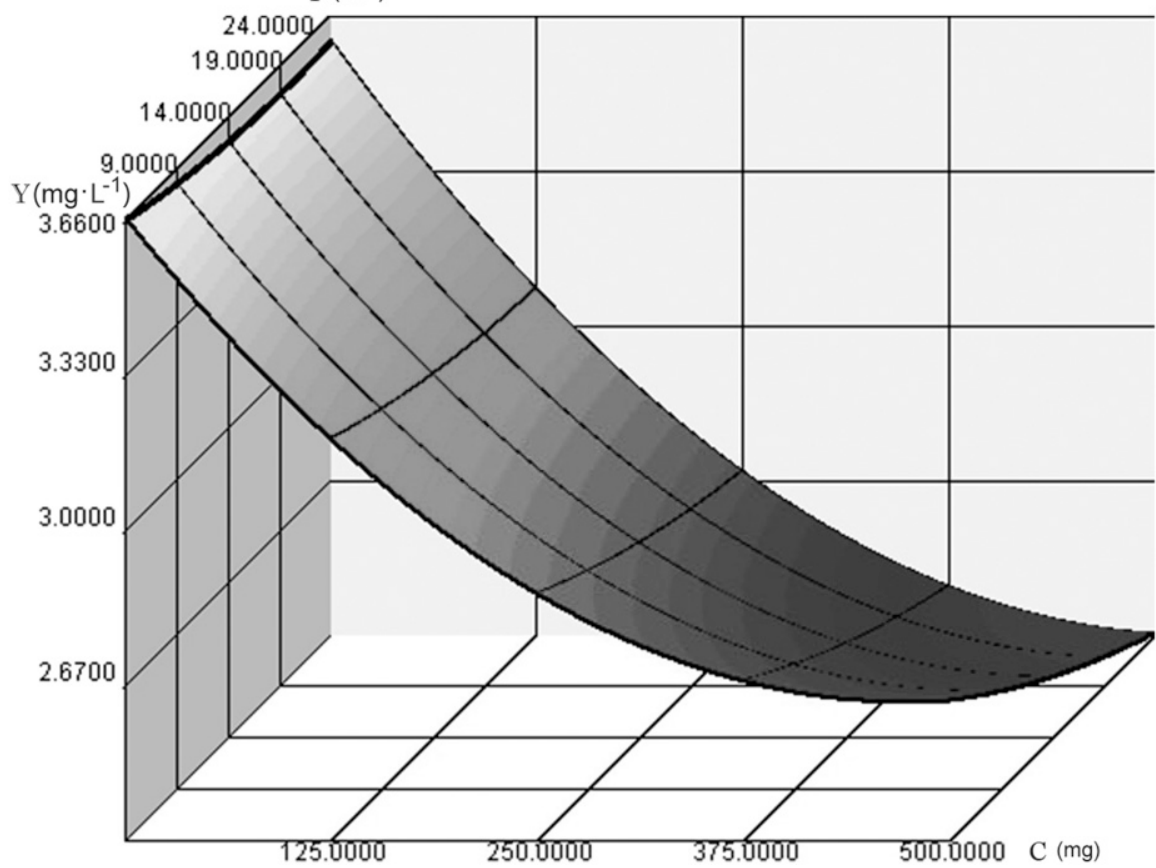

Fig. 1. Analysis of residual mass concentration of total nitrogen (TN) adsorbed by the oyster shell fragments by time $(\mathrm{T})\left[\hat{y}=\mathrm{TN}=3.708-0.003644 \mathrm{C}-0.009343 \mathrm{~T}-0.0000207 \mathrm{CT}+0.0000033 \mathrm{C}^{2}+\right.$ $\left.0.00023 \mathrm{~T}^{2}\left(F=44.7208^{* *}\right)\right]$. Three-dimensional response surface plot showing the effect that when $C=720 \mathrm{mg}$ and $T=52.6 \mathrm{~h}$, the residual amount reached a minimum value of $2.1499 \pm 0.2157 \mathrm{mg} \cdot \mathrm{L}^{-1}$.

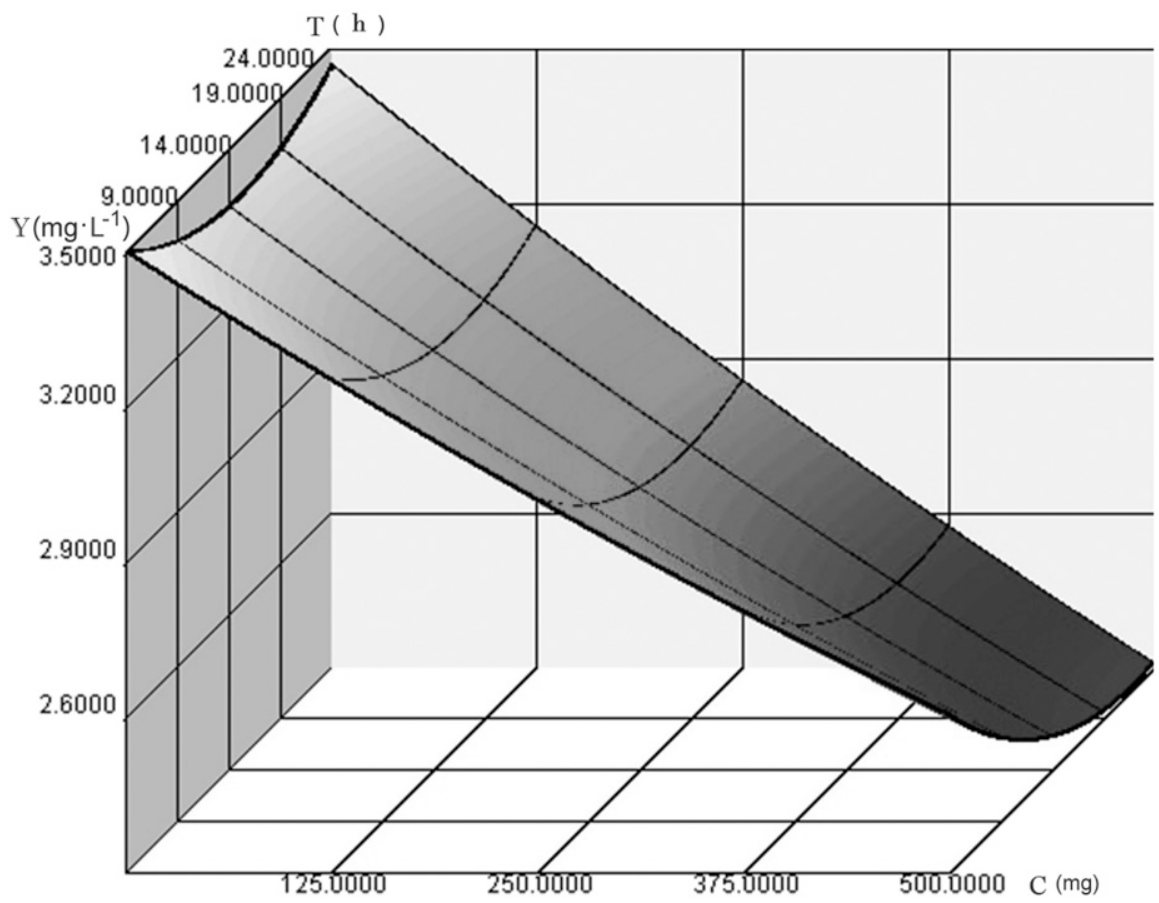

Fig. 2. Analysis of residual mass concentration of $\mathrm{NH}_{4}{ }^{+}-\mathrm{N}$ adsorbed by the oyster shell fragments by time (T) $\left[\hat{y}=\mathrm{NH}_{4}+-\mathrm{N}=3.606-0.001597 \mathrm{C}-0.02774 \mathrm{~T}-0.0000219 \mathrm{CT}+0.000000362 \mathrm{C}^{2}+0.0009245 \mathrm{~T}^{2}\right.$ $\left.\left(F=11.5375^{* *}\right)\right]$. Three-dimensional response surface plot showing the effect that when $C=4145 \mathrm{mg}$ and $T=64 \mathrm{~h}$, the residual amount reached a minimum value of $-0.5943 \pm 0.3435 \mathrm{mg} \cdot \mathrm{L}^{-1}$.

$0,125,250$, and $375 \mathrm{mg}$ were placed in four 5 L flow aquariums at $\mathrm{pH} 6.0$, and a sample solution was extracted at different time periods $(4,14$, and $24 \mathrm{~h})$. $\mathrm{N}$ and $\mathrm{P}$ adsorption on the differently sized oyster shell fragments were determined in 12 groups of flow aquariums and was repeated three times. The adsorption rate was calculated as $\eta=$ $\left(C_{0}-C_{\mathrm{x}}\right) / C_{0} \times 100 \%$, where $C_{0}$ is the initial mass concentration for $\mathrm{N}$ or $\mathrm{P}$ in $\mathrm{mg} \cdot \mathrm{L}^{-1}$ and $C_{\mathrm{x}}$ is the residual mass concentration after adsorption.
Dissolution of the oyster shell fragments at different $p H$ values and durations. The oyster shell fragments selected from the above test were soaked in 5-L phosphoric buffer (pH 5.7, 5.9, 6.1, 6.3, and 6.5) to test the dissolution at different $\mathrm{pH}$ values. The oyster shell fragments were removed regularly (every 1, 3, 5, 7, and $9 \mathrm{~h}$ ), dried, and the residual weight measured. The dissolution of the oyster shell fragments under different $\mathrm{pH}$ values and durations was recorded. The $\mathrm{pH}$ was determined using an acidometer. The experiments were repeated three times.

Oyster shell supplementation on $\mathrm{Ca}^{2+}$, $P A L$, and anthocyanins in A. andraeanum. The oyster shell fragments were combined with an Anthurium general nutrient solution (The nutrient solution was changed once a week.) The $\mathrm{Ca}^{2+}$ contents and PAL activity of the pedicels, and the anthocyanin content of the spathe of $A$. andraeanum treated at different treatment durations $(4,6,8,10$, and 12 weeks) were determined under weak light $\left(220 \mu \mathrm{mol} \cdot \mathrm{m}^{-2} \cdot \mathrm{s}^{-1}\right.$; Xia and Cai, 2004). The treatments were repeated three times. Atomic absorption spectrometry was used for the extraction and determination of $\mathrm{Ca}$ content. The extraction and determination of PAL used the method of Ouyang G.C. (1985). Briefly, $0.2 \mathrm{~g}$ of pedicels from A. andraeanum was combined with borate buffer containing $5 \mathrm{mmol} \cdot \mathrm{L}^{-1}$ rye-based ethanol, a small amount of polyvinylpyrrolidone (PVP), and sterile quartz sand. The mixture was ground in an ice bath and centrifuged at $12,000 \mathrm{rpm}$ for $15 \mathrm{~min}$, with the resulting supernatant constituting the crude enzyme extract. The supernatant was diluted four times with $1 \mathrm{~mL}$; was absorbed at $0.8 \mathrm{~mL}$; and was added to a $2 \mathrm{~mL} 0.1$ $\mathrm{mol} \cdot \mathrm{L}^{-1} \mathrm{pH} 8.8$ borate buffer containing 2.0 $\mathrm{mL} 0.02 \mathrm{~mol} \cdot \mathrm{L}^{-1} \mathrm{~L}$-phenylalanine, following which it was placed in a water bath at $30{ }^{\circ} \mathrm{C}$ for $1 \mathrm{~h}$. The supernatant was measured at $\mathrm{OD}_{290}$ with an ultraviolet spectrophotometer. The determination of anthocyanin content followed the method of the East China Normal University's Biological Department (ECNU, 1980). Briefly, $0.2 \mathrm{~g}$ of spathe from $A$. andraeanum was weighed and cut into $\approx 2$ to $3 \mathrm{~mm}$ fragments. The fragments were then placed into a plugged test tube. Twenty milliliters of $0.1 \mathrm{~mol} \cdot \mathrm{L}^{-1} \mathrm{HCl}$ was added to the test tube, which was then placed in a constant temperature water bath at $32{ }^{\circ} \mathrm{C}$ for $4 \mathrm{~h}$. The filtrate was filtered and measured spectrophotometrically at $\mathrm{OD}_{530}$. The relative concentration unit of the anthocyanins was expressed 10 times.

Data analysis. The data were processed by Microsoft Excel 2013 and analyzed in SPSS Statistics 20.0 (IBM Corp., Armonk, $\mathrm{NY}$ ). A nonlinear regression model with the quadratic function $y=a+b x+c x^{2}$ was used to analyze the results of each index in single factor and multilevel tests. Using the RSM, the following second-order polynomial equation $y=b_{0}+b_{1} x_{1}+b_{2} x_{2}+b_{3} x_{1} x_{2}+$ $b_{4} x_{1}^{2}+b_{5} x_{2}^{2}$ was used to analyze the results of each index in a complex factor and 
$\mathrm{T}(\mathrm{h})$

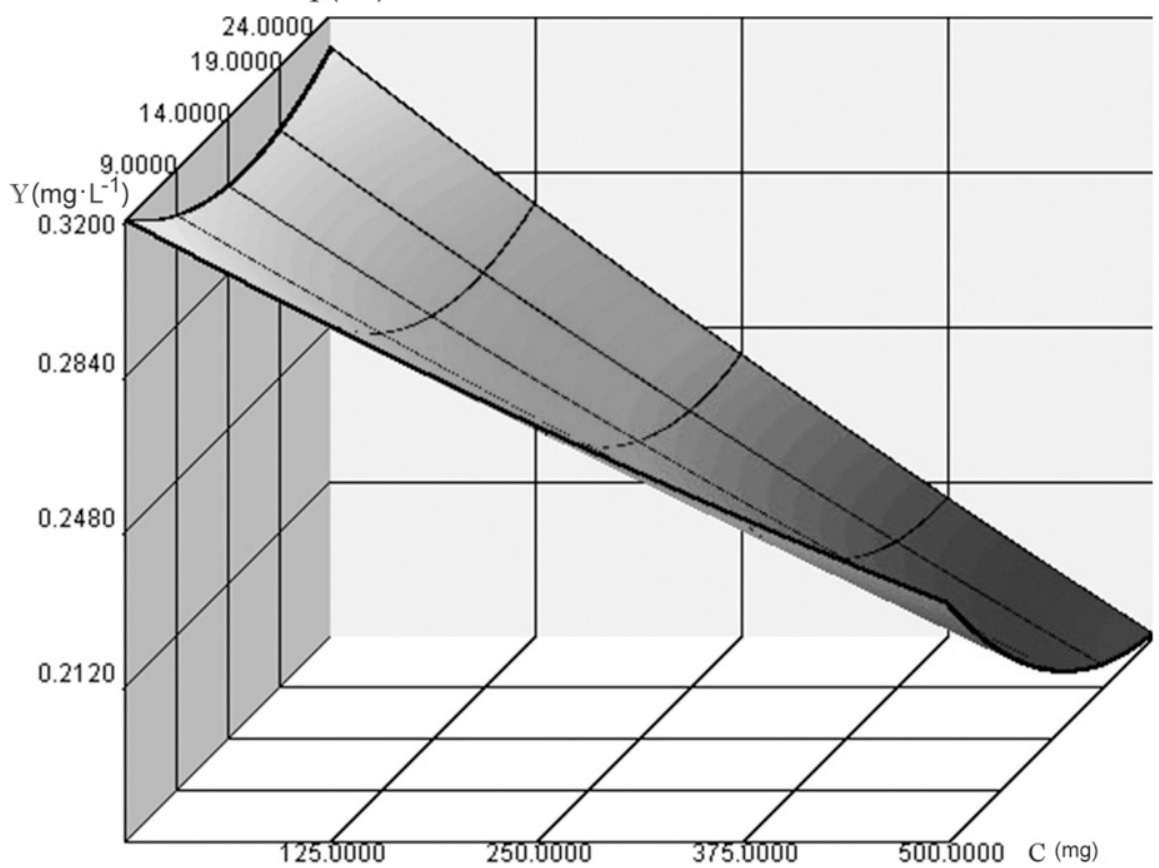

Fig. 3. Analysis of residual mass concentration of TP adsorbed by the oyster shell fragments by time (T) $\left[\hat{y}=\mathrm{TP}=0.3349-0.000155 \mathrm{C}-0.003826 \mathrm{~T}-0.000004 \mathrm{CT}+0.000000038 \mathrm{C}^{2}+0.000122 \mathrm{~T}^{2}(F=\right.$ $5.2792 *)$ ]. Three-dimensional response surface plot showing the effect that when $C=20,738 \mathrm{mg}$ and $T=354 \mathrm{~h}$, the residual amount reached a minimum value of $-1.9529 \pm 0.0593 \mathrm{mg} \cdot \mathrm{L}^{-1}$.

$\mathrm{T}(\mathrm{h})$

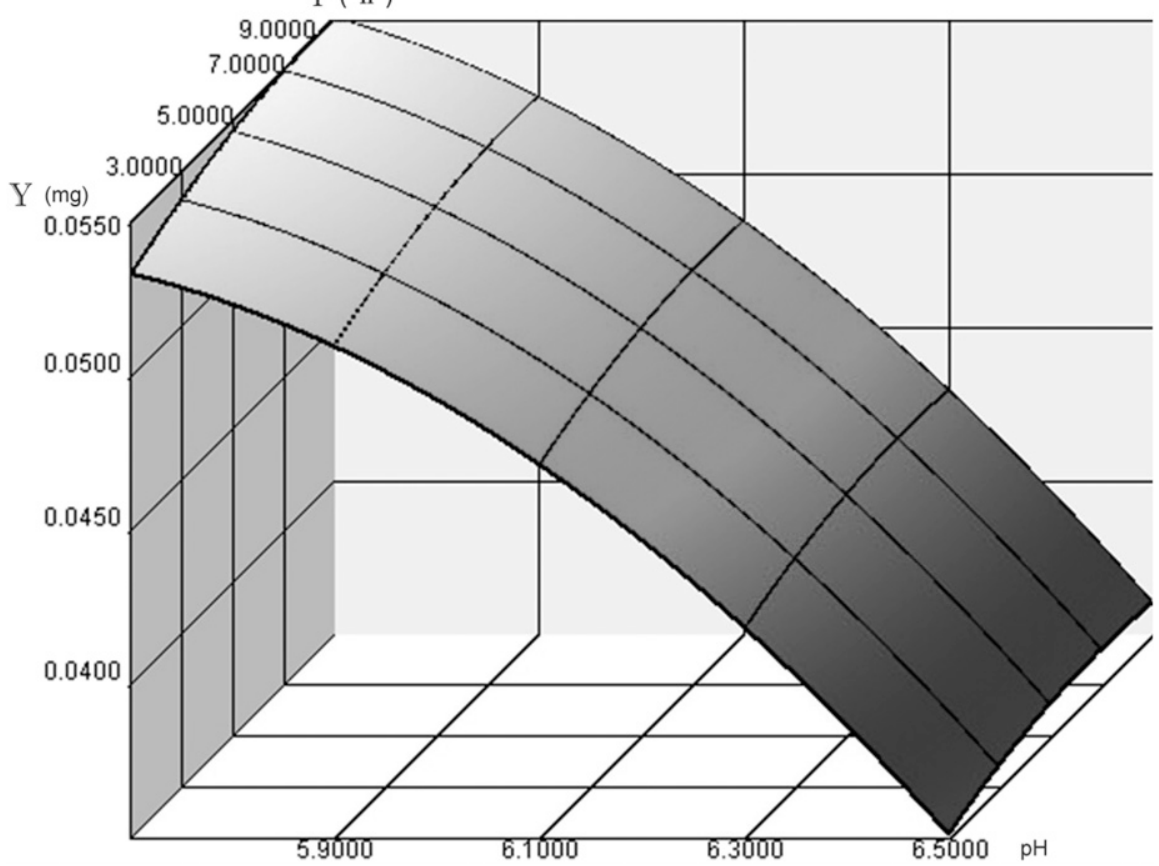

Fig. 4. Analysis of oyster shell fragments solubility (mg) under different $\mathrm{pH}$ values and time [T (h)] $\left[\hat{y}=\right.$ dissolution $=0.503+0.2033 \mathrm{pH}+0.001253 \mathrm{~T}-0.00125 \mathrm{pHT}-0.01857 \mathrm{pH}^{2}-0.000032 \mathrm{~T}^{2}$ $\left.\left(F=90.4048^{* *}\right)\right]$. Three-dimensional response surface plot showing the effect that when $\mathrm{pH}=$ $5.4461, T=8.916 \mathrm{~h}$, the solubility reached a maximum value of $0.0564 \pm 0.0032 \mathrm{mg}$.

multilevel test. The fit of the model was assessed using the coefficient of determination $\left(R^{2}\right)$ and the adjusted $R^{2}$. The fitted polynomial equation was then illustrated using three-dimensional surface plots to visualize the relationships among the responses of the variables.

\section{Results and Analysis}

Analysis of the adsorption of $\mathrm{N}$ and $\mathrm{P}$ and the $\mathrm{Ca}$ released by dissolution from the oyster shell fragments

Analysis of the adsorption of $N$ and $P$ by the oyster shell fragments. The residual mass concentrations following adsorption are shown in Figs. 1-3. The adsorption of TN, $\mathrm{NH}_{4}{ }^{+}-\mathrm{N}$, and TP from the oyster shells increased rapidly at first and then slowed down as time progressed. Within $4 \mathrm{~h}$, the adsorption rate increased rapidly, slowing down after 14 $\mathrm{h}$. One possible explanation is that the adsorption is mainly carried out on the surface of the oyster shell fragments or in the pores during the first $4 \mathrm{~h}$, following which the increase in microporous ions in the oyster shell produces repulsion. This pattern would prevent the ions from approaching the oyster shell fragments in solution, thus slowing down the adsorption rate. The adsorption rates of $\mathrm{TN}, \mathrm{NH}_{4}{ }^{+}-\mathrm{N}$, and TP using 125-mg oyster shell fragments after $24 \mathrm{~h}$ were $55.6 \%, 39.1 \%$, and $30.6 \%$, respectively ( $\mathrm{TN}>\mathrm{NH}_{4}{ }^{+}-\mathrm{N}>\mathrm{TP}$ ), while these values were $57 \%, 49.5 \%$, and $47.2 \%(\mathrm{TN}>$ $\mathrm{NH}_{4}{ }^{+}-\mathrm{N}>\mathrm{TP}$ ), respectively, after $24 \mathrm{~h}$ using the $375 \mathrm{mg}$ oyster shell fragments. The differences in adsorption rates were much more narrow in comparison with the $125-\mathrm{mg}$ oyster shell fragments.

The adsorption of $\mathrm{TN}$ and $\mathrm{NH}_{4}^{+}-\mathrm{N}$ differed significantly between the different oyster shell treatments $\left(F>F_{0.01}=8.7459\right)$, whereas no significant difference in the adsorption of $\mathrm{TP}$ was observed $\left(F>F_{0.05}=\right.$ 4.3874) (Figs. 1-3). The results indicate that adsorption increases with increases in oyster shell size, with the 375-mg oyster shell fragments exhibiting the best adsorption.

Effect of different $p H$ values on the dissolution and release of Ca from the oyster shell fragments. The 375-mg oyster shell fragments were selected based on the above experiment, and the effects of different $\mathrm{pH}$ values $(5.7,5.9,6.1,6.3$, and 6.5 , respectively) on the dissolution and release of $\mathrm{Ca}$ from the shell were tested. The results are shown in Fig. 4. The dissolution of the oyster shell fragments was significantly correlated with $\mathrm{pH}$ and time $\left(F=90.4048^{* *}, F_{0.01}=4.1708\right.$, $\left.F>F_{0.01}\right)$. According to the RSM analysis (Fig. 4), the solubility of the oyster shell fragments increased with the increase in treatment time but decreased with the increase in $\mathrm{pH}$ value. The lower the $\mathrm{pH}$ value and the longer the treatment duration, the greater the solubility. At $\mathrm{pH}=5.4461$ and $T=8.916$ $\mathrm{h}$, the solubility of the oyster shell fragments peaked $0.0564 \pm 0.0032 \mathrm{mg}$.

At the same time, the $\mathrm{pH}$ value of Anthurium soilless culture in actual production is between 5.5 and 6.5. Considering the adsorption effect of $375 \mathrm{mg}$ and a $6.0 \mathrm{pH}$ value of oyster shell fragments, $\mathrm{pH}=5.9$ was selected for the following experiments.

\section{Effects of temperature and light intensity (PFD) on PAL activity and anthocyanin content in $A$. andraeanum}

Comparative experiments of the effects of light and different temperatures on the growth of $A$. andraeanum showed that temperatures above $30{ }^{\circ} \mathrm{C}$ were too high for the plants, whereas temperatures below $15{ }^{\circ} \mathrm{C}$ resulted in yellow leaves, green back, and other harmful symptoms that significantly affected plant growth and development. 


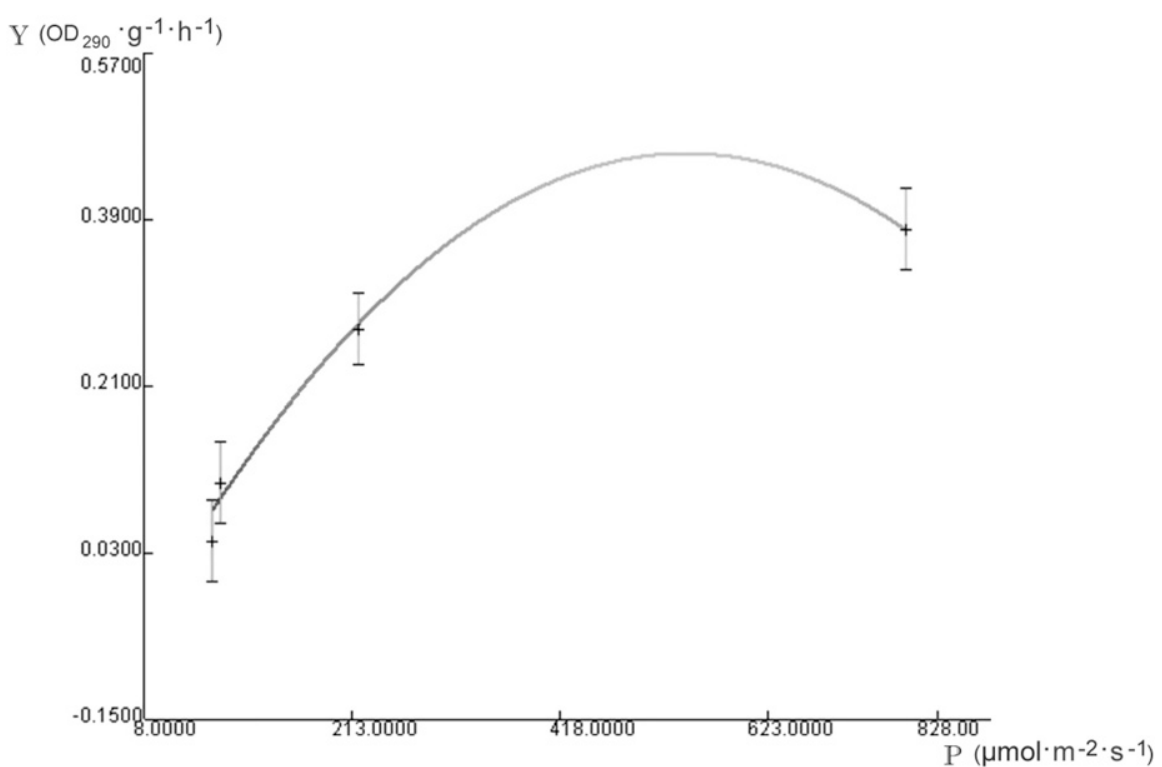

Fig. 5. Effects of PFD treatment with different light intensity on phenylalanine ammonia lyase (PAL) activity in pedicel $\left[\hat{y}=\mathrm{PAL}=-0.0616+0.0016 \mathrm{P}-0.000001757 \mathrm{P}^{2}\left(F=0.7981<F_{0.05}\right)\right]$. Twodimensional response surface plot showing the effect that when $P=543$, PAL activity has a maximum value of $0.4572 \pm 0.1492\left(\mathrm{OD}_{290} \cdot \mathrm{g}^{-1} \cdot \mathrm{h}^{-1}\right)(r=0.921$, probability guarantee is 0.9081$)$

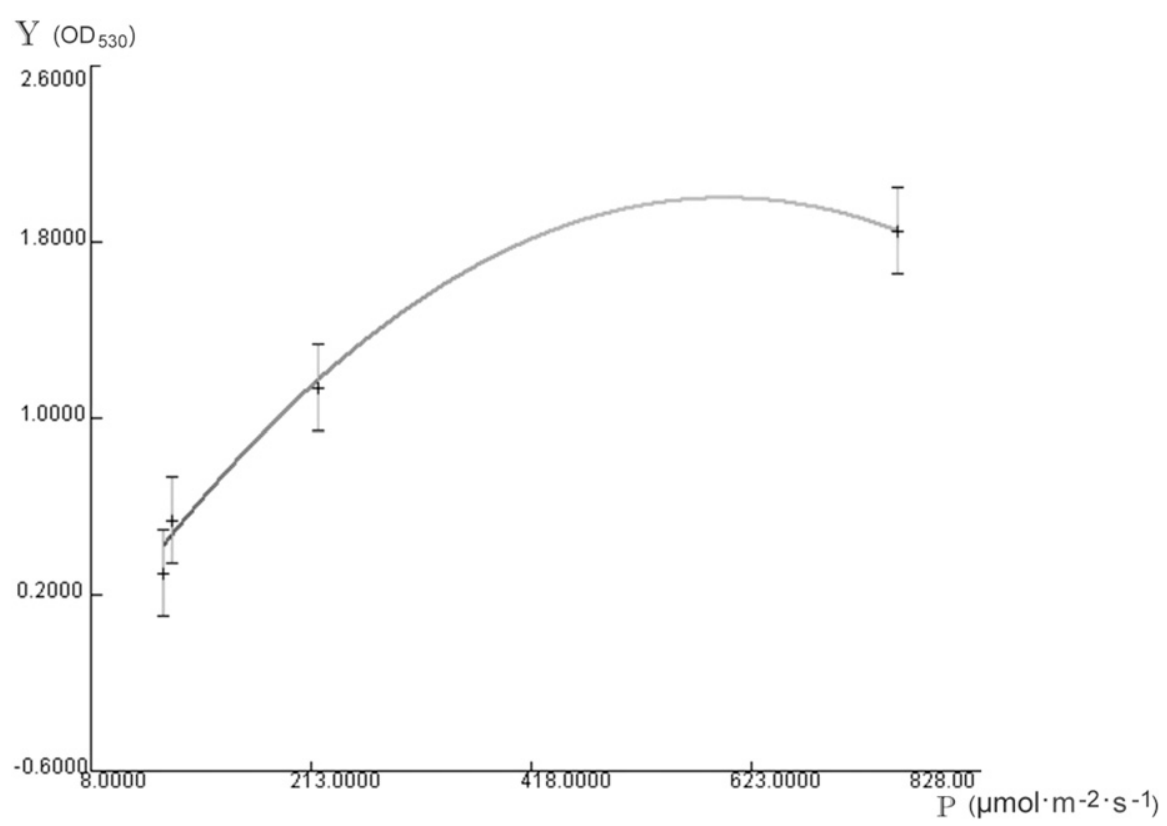

Fig. 6. Effects of PFD treatment with different light intensity on anthocyanin content in spathe $[\hat{y}=$ anth $=$ $\left.-0.08235+0.0068 \mathrm{P} \pm 0.00000568 \mathrm{P}^{2}\left(F=1.9024<F_{0.05}\right)\right]$. Two-dimensional response surface plot showing the effect that when $P=599$, anthocyanin has a maximum value of $1.956 \pm 0.8177\left(\mathrm{OD}_{530}\right)$ $(r=0.889$; probability guarantee is 0.8267$)$.

PAL activity and anthocyanin content in A. andraeanum under different light intensities at suitable cultivation temperatures ( 16 to $29{ }^{\circ} \mathrm{C}$ ) confirmed that weak light intensity below $220 \mu \mathrm{mol} \cdot \mathrm{m}^{-2} \cdot \mathrm{s}^{-1}$ could inhibit PAL activity and reduce anthocyanin content. Regression analysis showed that the PAL activity in the pedicels increased initially and then decreased with the increase in light intensity (Figs. 5 and 6). At $P=543$ ( $P$ stands for light intensity, $\left.\mu \mathrm{mol} \cdot \mathrm{m}^{-2} \cdot \mathrm{s}^{-1}\right)$, the PAL activity reached the maximum value $0.4572 \pm$ $0.1492\left(\mathrm{OD}_{290} \cdot \mathrm{g}^{-1} \cdot \mathrm{h}^{-1}\right)$. While PAL activity correlation $r=0.889$ and determination 0.8267 coefficients were somewhat low, suggesting that light intensity may indirectly influence anthocyanin content.

\section{Effects of oyster shell fragment mass $C$ (mg) and cultivation time $T$ (weeks) on PAL activity in the pedicles}

The PAL activity in the pedicels cultivated under weak light $\left(220 \mu \mathrm{mol} \cdot \mathrm{m}^{-2} \cdot \mathrm{s}^{-1}\right)$ was determined by applying a general formula nutrient solution supplemented with shell fragments. The effects of $C(\mathrm{mg})$ and $T$ (weeks) treatment on the activity of PAL in the pedicels were studied. Regression analysis showed that the PAL activity in the pedicel first rose and then decreased with the increase in oyster shell fragment mass $C$ (Fig. 7). When $C=286(\mathrm{mg})$ and $T=8.1$ (weeks), the activity of PAL reached the maximum value of $0.2936 \pm 0.0838\left(\mathrm{OD}_{290} \cdot \mathrm{g}^{-1} \cdot \mathrm{h}^{-1}\right)$; when $C$ exceeded $286 \mathrm{mg}$, the activity of PAL decreased with the increase in time. One possible explanation is that the increased duration resulted in a higher cumulative $\mathrm{Ca}$ content, which inhibited PAL activity and resulted in a decrease in PAL activity. There were significant differences in PAL activity between oyster shell fragment mass and time $\left(F=4.1232 *, F_{0.05}=\right.$ 2.7401, $F>F_{0.05}$ ).

The results of the single factor test time for PAL activity showed that there was no significant interaction between PAL activity and the single factor of time $(F=0.7857$, $\left.F_{0.05}=19.00, F<F_{0.05}\right)$; but when $T=7.4$ (weeks), PAL activity had a maximum value of $0.2973 \pm 0.0161\left(\mathrm{OD}_{290} \cdot \mathrm{g}^{-1} \cdot \mathrm{h}^{-1}\right)$. PAL activity was significantly affected by oyster shell fragment mass $\left(F=4.1232 *>F_{0.05}\right)$, but not by time.

\section{Content changes of $\mathrm{Ca}^{2+}$ in the pedicles and anthocyanin in the spathe under oyster shell cultivation}

The contents of $\mathrm{Ca}^{2+}$ in the pedicels and anthocyanins in the spathe were determined under cultivation with $375 \mathrm{mg}$ oyster shell fragments.

$\mathrm{Ca}^{2+}$ content in the pedicels increased first and then decreased with the increase in treatment time. $\mathrm{Ca}^{2+}$ content $(\mathrm{mg})$ and treatment time (weeks) were not significantly associated $\left(F=1.694, F_{0.05}=19.00, F<\right.$ $\left.F_{0.05}\right)$, indicating that the increase in $\mathrm{Ca}^{2+}$ content was not significant with time. However, at $T=8.5$ (weeks), the $\mathrm{Ca}^{2+}$ content had a maximum value of $0.4900 \pm 0.0482(\mathrm{mg})$. It is possible that the accumulation of $\mathrm{Ca}^{2+}$ (with higher absolute value) inhibits PAL activity due to the increase of solubility of oyster shell piece. This characteristic can also be inferred from the correspondence of the peak values of $\mathrm{Ca}^{2+}$ and PAL (Figs. 8 and 9) occurring simultaneously in the eighth week.

The effect of $T$ on anthocyanin content in the spathe showed an increasing trend with the increase in treatment time (Fig. 10). Increased time was associated with increased anthocyanin accumulation, with a significant interaction detected between anthocyanin 


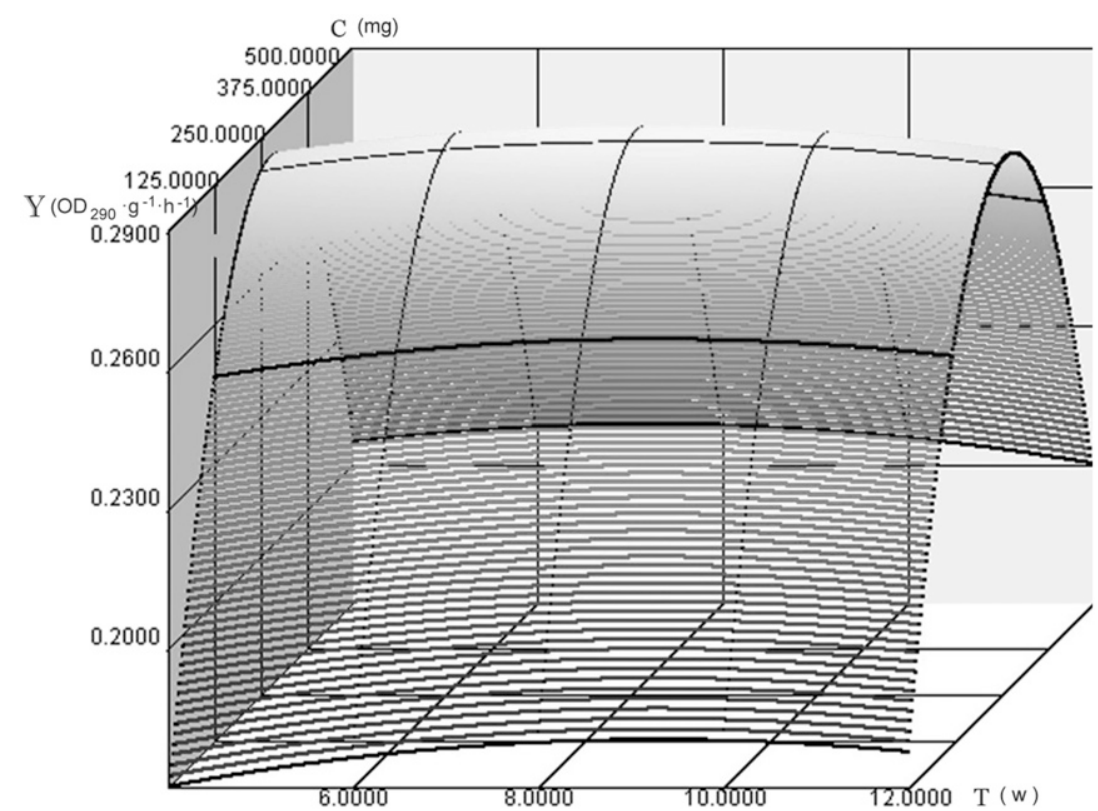

Fig. 7. Effects of oyster shell fragments' quality $\mathrm{C}(\mathrm{mg})$ and time $[\mathrm{T}(\mathrm{w})]$ treatment on phenylalanine ammonia lyase (PAL) $\left(\mathrm{OD}_{290} \cdot \mathrm{g}^{-1} \cdot \mathrm{h}^{-1}\right)$ activity of the pedicle in Anthurium $[\hat{y}=$ PAL $=0.1169+0.0068 \mathrm{~T}+0.001 \mathrm{C}-0.0000033 \mathrm{TC}-0.0003607 \mathrm{~T}^{2}-0.000001772 \mathrm{C}^{2}(F=$ 4.1232*)]. Three-dimensional response surface plot showing the effect that when $T=8.1438 \mathrm{w}$, $C=286.07 \mathrm{mg}$, then PAL activity has a maximum value of $0.2936 \pm 0.0838\left(\mathrm{OD}_{290} \cdot \mathrm{g}^{-1} \cdot \mathrm{h}^{-1}\right) . \mathrm{w}=$ week

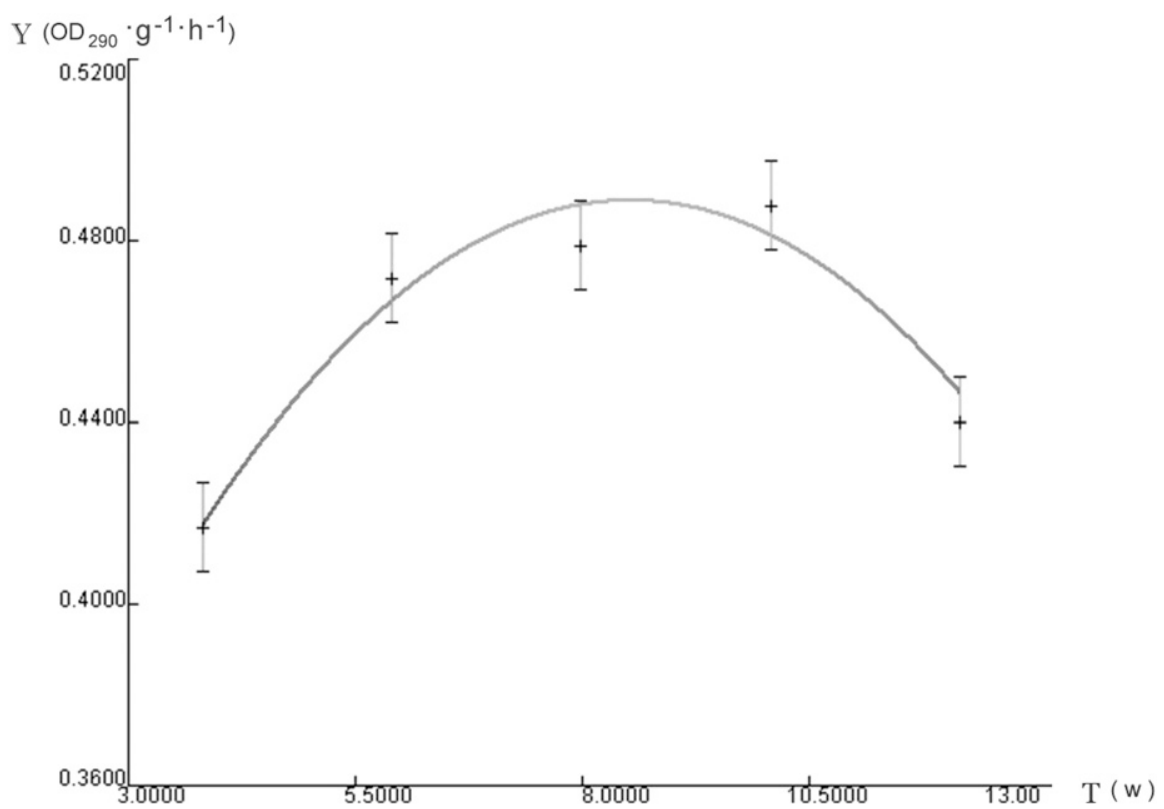

Fig. 8. Effects of time $[\mathrm{T}(\mathrm{w})]$ treatment on phenylalanine ammonia lyase $(\mathrm{PAL})\left(\mathrm{OD}_{290} \cdot \mathrm{g}^{-1} \cdot \mathrm{h}^{-1}\right)$ activity of the pedicle in Anthurium $\left[\hat{y}=\mathrm{PAL}=0.2562+0.0111 \mathrm{~T}-0.00075 \mathrm{~T}^{2}(F=0.7857)\right]$. Two-dimensional response surface plot showing the effect that when $T=7.4 \mathrm{w}$, PAL activity has a maximum value of $0.2973 \pm 0.0161\left(\mathrm{OD}_{290} \cdot \mathrm{g}^{-1} \cdot \mathrm{h}^{-1}\right)$. w $=$ week

content and treatment time $\left(F=28.5261^{*}\right.$, $F_{0.05}=19.00, F>F_{0.05}$ ). At $T=3.1$ (weeks), the minimum anthocyanin content was $0.6723 \pm 0.0342\left(\mathrm{OD}_{530}\right)$.

\section{Discussion and Conclusion}

The results show that larger oyster shell fragments are associated with improved adsorption of $\mathrm{N}$ and $\mathrm{P}$, with adsorption increasing
The microdissolution has a significant relationship with the $\mathrm{pH}$ value and time.

In the soilless culture of $A$. andraeanum using oyster shell fragments as a substrate, weak light intensity below $220 \mu \mathrm{mol} \cdot \mathrm{m}^{-2} \cdot \mathrm{s}^{-1}$ could inhibit PAL activity and reduce anthocyanin content. The effect of light intensity on PAL was higher than that on anthocyanins, indicating an indirect impact on anthocyanins (Gopaulchan et al., 2014; Xia and Cai, 2004). The $\mathrm{Ca}^{2+}$ released from the $286 \mathrm{mg}$ oyster shell fragments at $\mathrm{pH} 5.5$ significantly increased PAL activity in the pedicel under weak light within $8 \mathrm{~h}$. In the $375 \mathrm{mg}$ oyster shell fragment treatment at $\mathrm{pH}$ 5.9 , the PAL activity of the pedicel was significantly increased under weak light. At 8 weeks, the $\mathrm{Ca}^{2+}$ content and PAL activity of the pedicel peaked, which significantly increased the anthocyanin content of the spathe, following which the anthocyanin content continued to increase. This finding suggests that the increase in anthocyanin content may depend on the increase of $\mathrm{Ca}^{2+}$ content and PAL activity over 8 weeks. Later, it is related to the slow release of $\mathrm{N}$ and $\mathrm{P}$ elements from oyster shell pieces to synthesize protein and sugar (Higaki et al., 1992).

$\mathrm{CaCl}_{2}$ can effectively increase PAL activity and anthocyanin content in the pedicel (AvilaRostant et al., 2010). It is proved that $\mathrm{Ca}^{2+}$ can overcome the decrease in photosynthate (mainly sugars) accumulation and PAL activity caused by insufficient sunlight (Wang, 1999; Wang et al., 2018) and can provide sufficient precursors and pathways for the synthesis of anthocyanins, thereby increasing anthocyanin content (Yang et al., 2015). The use of exogenous $\mathrm{Ca}^{2+}$ derived from oyster shell waste not only alleviates the environmental pollution caused by unused oyster shells but also offers a solution for improving the cultivation of $A$. andraeanum. In the future, it can also be used as a typical plant landscaping model under the tropical valley rainforest.

\section{Literature Cited}

Avila-Rostant, O., A.M. Lennon, and P. Umaharan 2010. Spathe color variation in Anthurium andraeanum Hort. and its relationship to vacuolar pH. HortScience 45:1768-1772.

Chang, K.H., R.Y. Wu, G.P. Chang, T.F. Hsieh, and R.S. Chung. 2012. Effects of nitrogen concentration on growth and nutrient uptake of Anthurium andraeanum Lind. cultivated in coir under different seasonal conditions. HortScience 47:515-521.

Dufour, L. and V. Guerin. 2003. Growth, developmental features and flower production of $A n-$ thurium andraeanum Lind. in tropical regions. Scientia Hort. 98(1):25-35.

East China Normal University (ECNU). 1980 Instruction for plant physiology experiments. Editor-in-chief, Physiology Teaching and Research Group, Department of Biology. People's Education Publishing House, Beijing, China [in Chinese].

Ouyang, G.C. 1985. Determination of phenylalanine ammonia lyase (PAL) activity, p. 191. In: Handbook of plant physiology experiments. Editor-in-chief, Shanghai Society of Plant Physiology. Shanghai Science and Technology Publishing House, Shanghai, China [in Chinese].

Gopaulchan, D., P. Umaharan, and A.M. Lennon. 2014. A molecular assessment of the genetic 


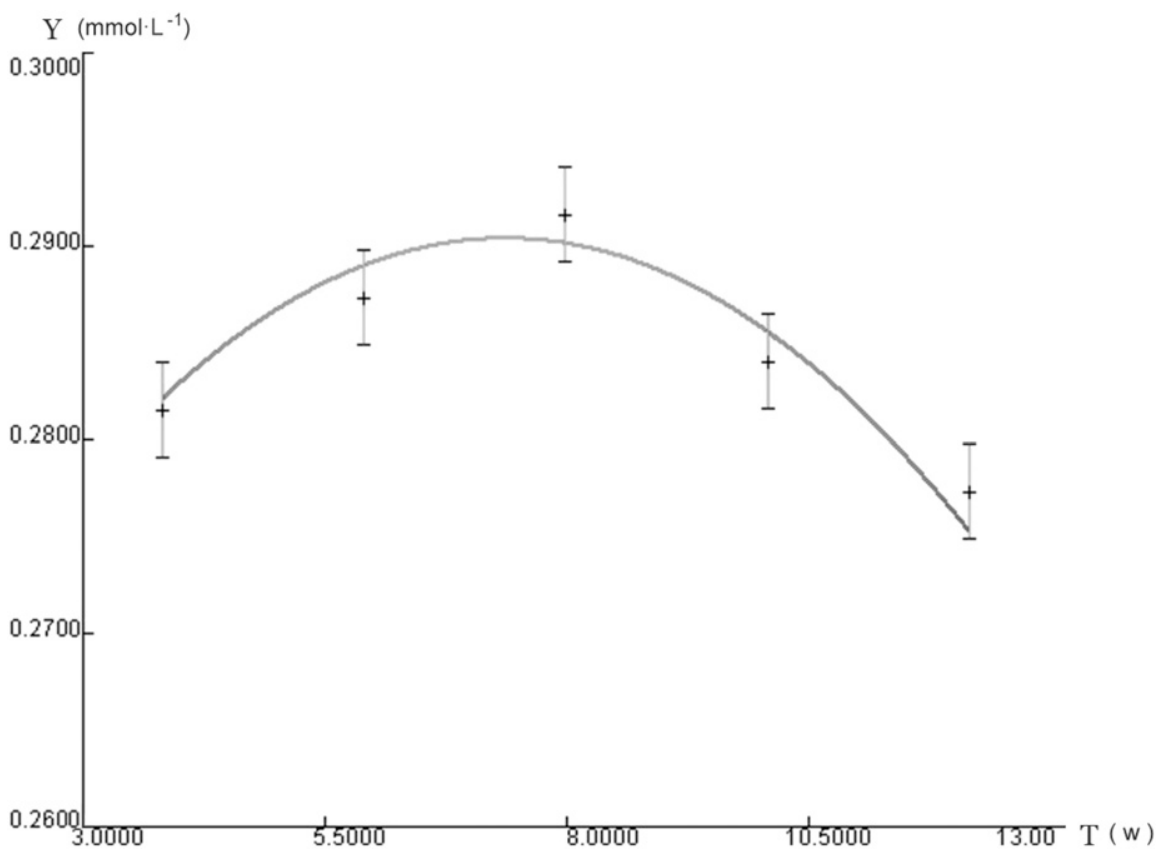

Fig. 9. Effects of time $[\mathrm{T}(\mathrm{w})]$ treatment on $\mathrm{Ca}^{2+}\left(\mathrm{mmol} \cdot \mathrm{L}^{-1}\right)$ content in Anthurium pedicel $\left[\hat{y}={ }_{\mathrm{Ca} 2+}=0.2439\right.$ $\left.+0.05778 \mathrm{~T} \pm 0.003392 \mathrm{~T}^{2}(F=1.694)\right]$. Two-dimensional response surface plot showing the effect that when $T=8.5158 \mathrm{w}, \mathrm{Ca}^{2+}$ content has a maximum value of $0.4900 \pm 0.0482\left(\mathrm{mmol} \cdot \mathrm{L}^{-1}\right) . \mathrm{w}=$ week

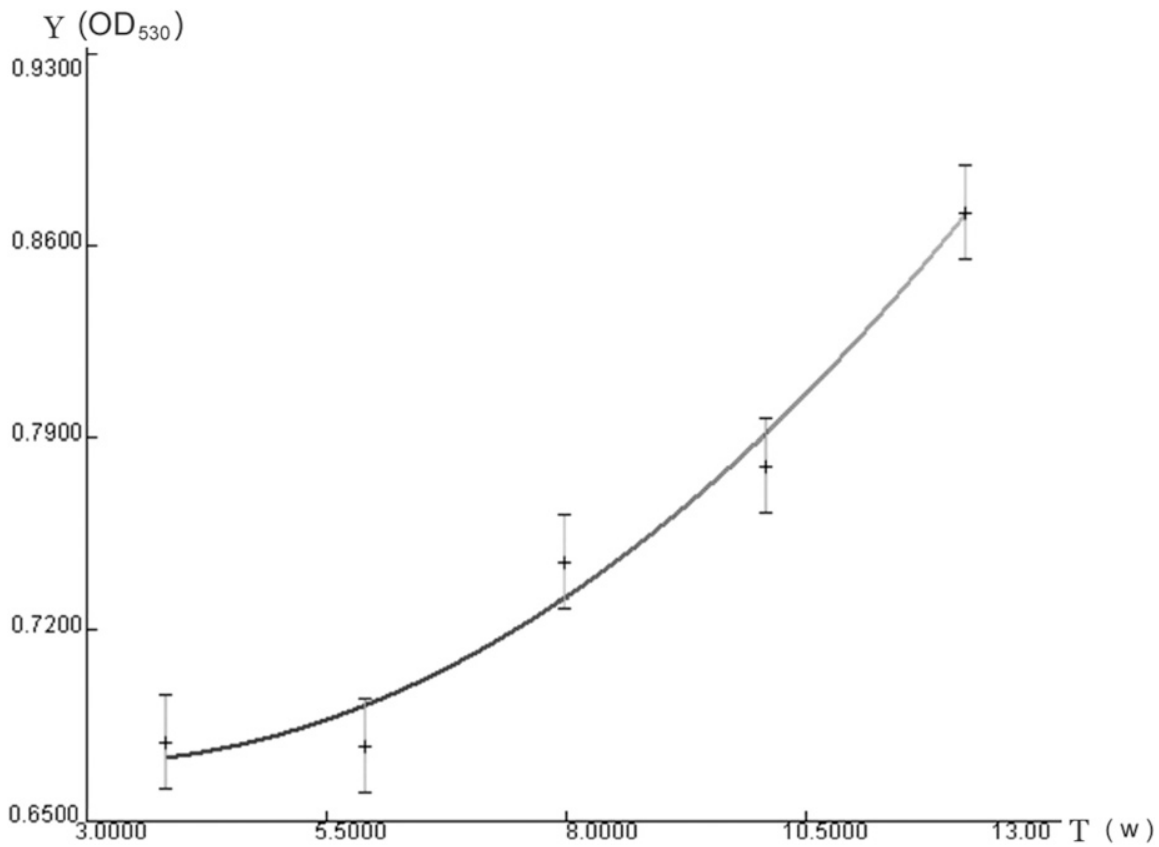

Fig. 10. Effects of time $[\mathrm{T}(\mathrm{w})]$ treatment on anthocyanin $\mathrm{OD}_{530}$ content in Anthurium spathe $\left[\hat{y}={ }_{\text {anth }}=0.6967 \pm\right.$ $\left.0.01577 \mathrm{~T}+0.002535 \mathrm{~T}^{2}\left(F=28.5261^{* *}\right)\right]$. Two-dimensional response surface plot showing the effect that when $\mathrm{T}=3.1099 \mathrm{w}$, anthocyanin content has a minimum value of $0.6723 \pm 0.0342\left(\mathrm{OD}_{530}\right) . \mathrm{w}=$ week model of spathe color inheritance in Anthurium andraeanum Hort. Planta 239(3):695-705.

Henny, R.J. and R.L. Hamilton. 1992. Flowering of Anthurium following treatment with gibberellic acid. HortScience 27:1328

Higaki, T., J.S. Imamura, and R.E. Paull. 1992 $\mathrm{N}$, $\mathrm{P}$, and $\mathrm{K}$ rates and leaf tissue standards for optimum Anthurium andraeanum flower production. HortScience 27:909-912.

Higaki, T., H.P. Tasmussen, and W.J. Carpenter. 1980. Color breakdown in Anthurium spathes caused by calcium deficiency. J. Amer. Soc. Hort. Sci. 105:441-444.

Li, C.H., J.H. Niu, and S.R. Huang. 2015. Preliminary studies on partial mutation in color of Anthurium andraeanum 'Arizona'spathe. Mol Plant Breed. 13(3):627-633 [in Chinese].

Liu, S.M. 2004. Study on the physiological and biochemical effects of oyster shell soil conditioner on ginseng. China Ocean University, Qingdao, China [in Chinese]

Miao, Y.L., P.Z. Hong, and W.D. Song. 2007. Preliminary study on preparation of slow-release nitrogen fertilizer from oyster shell powder. J. Guangdong Ocean Univ. 27(6):86-88 [in Chinese].

Teng, J., Q. Wang, W. Ran, D. Wu, Y.F. Liu, S. Sun, H. Liu, R.W. Cao, and J.M. Zhao. 2019. Microplastic in cultured oysters from different coastal areas of China. Sci. Total Environ. 653:1282-1292.

Wang, H.F. 1997. Soilless cultivation of flowers Jindun Publishing House, Beijing, China [in Chinese].

Wang, H.L. 1999. Effects of low temperature storage on sugar content, respiration rate and quality of Anthurium indicum. Plant Physiological Communication 35(6):458-460 [in Chinese].

Wang, L.L., G.S. Yang, and C.H. Li. 2012. Physiological causes of the occurrence of "green ear" in the bud of Anthurium andraeanum in Hainan. Acta Hort. Sinica 39(5):939948 [in Chinese].

Wang, Y., S. Liu, X. Tian, Y. Fu, X. Jiang, Y. Li, and G. Wang. 2018. Influence of light intensity on chloroplast development and pigment accumulation in the wild-type and etiolated mutant plants of Anthurium andraeanum 'Sonate' Plant Signal. Behav. 13(8):e1482174.

Xia, C.H. and S.Y. Cai. 2004. Effects of $\mathrm{GA}_{3}$ and $\mathrm{Ca}^{2+}$ on anthocyanin content and PAL activity of pedicels in Anthurium andraeanum spathe Acta Hort. Sinica 31(3):343-346 [in Chinese].

Yang, Y.X., X.X. Chen, B. Xu, Y.X. Li, Y.H. Ma, and G.G. Wang. 2015. Phenotype and transcriptome analysis reveal chloroplast development and pigment biosynthesis together influenced the leaf color formation in mutants of Anthurium andraeanum 'Sonate'. Front. Plant Sci. 6:139. 